\title{
Medical management of secretory syndromes related to gastroenteropancreatic neuroendocrine tumours
}

\author{
Georgios K Dimitriadis1,2,3, Martin O Weickert1,2,4, Harpal S Randeva1,2,4, \\ Gregory Kaltsas ${ }^{1,5,6}$ and Ashley Grossman'
}

1The Arden NET CoE, Warwickshire Institute for the Study of Diabetes, Endocrinology and Metabolism, University Hospitals of Coventry and Warwickshire NHS Trust, Coventry, UK

2Division of Translational and Experimental Medicine, Warwick Medical School, University of Warwick, Coventry, UK ${ }^{3}$ Division of Endocrinology and Investigative Medicine, Imperial College London, Hammersmith Campus, London, UK ${ }^{4}$ Centre for Applied Biological and Exercise Sciences, Coventry University, Coventry, UK

${ }^{5}$ Division of Pathophysiology, National and Kapodistrian University of Athens Medical School, Athens, Greece

${ }^{6}$ Oxford Center for Diabetes, Endocrinology and Metabolism, University of Oxford, Oxford, UK
Correspondence should be addressed to G K Dimitriadis Email

g.dimitriadis@warwick.ac.uk

\begin{abstract}
Although recent epidemiological evidence indicates that the prevalence of non-functioning gastroenteropancreatic (GEP) neuroendocrine tumours (NETs) is rising, a significant number of GEP-NETs still present with symptoms related to the secretion of biologically active substances leading to the development of distinct clinical syndromes. In the past, these syndromes were associated with substantial morbidity and mortality due to the lack of specific therapies; however, since the introduction of long-acting somatostatin analogues and medications such as proton pump inhibitors, their control has been greatly improved. As a result, nowadays, the main cause of morbidity and mortality in GEP-NETs is mostly directly related to tumour growth and the extent of metastatic disease. However, in some patients with functioning tumours and extensive disease, control of the secretory syndrome still remains problematic, necessitating the employment of several cytoreductive techniques, which may not always be sufficient. Recently, new agents directed against tumour growth, or exerting increased binding activity to receptors expressed in these tumours, or interfering with the synthetic pathway of some of the compounds secreted by these tumours, have been developed. Since there are no specific guidelines addressing the totality of the management of the secretory syndromes related to GEP-NETs, this review aims at critically analysing the medical management of previously recognised secretory syndromes; it also addresses areas of uncertainty, assesses the newer therapeutic developments and also addresses recently described but poorly characterised secretory syndromes related to GEP-NETs.
\end{abstract}

Key Words
neuroendocrine tumours
secretory syndrome
carcinoid syndrome
- insulinoma
- VIPoma
glucagonoma
- ectopic hormonal
secretion

Endocrine-Related Cancer (2016) 23, R423-R436
○ 2016 Society for Endocrinology Printed in Great Britain
Published by Bioscientifica Ltd 


\section{Introduction}

Gastroenteropancreatic (GEP) neuroendocrine tumours (NETs) are considered to be relatively rare, with an estimated incidence of 3-5 cases per 100,000 inhabitants; however, recent data indicate that their prevalence is increasing following the introduction of newer more sensitive biochemical and imaging modalities (Modlin et al. 2008, Huguet et al. 2015). In the past GEP-NETs came to medical attention due to their ability to secrete biologically active substances leading to the development of characteristic clinical syndromes (functioning tumours). Nowadays the majority of GEP-NETs do not cause secretory syndromes and present with metastases or symptoms of mass effect (non-functioning tumours) (Kaltsas et al. 2004). Neuroendocrine tumours are considered to originate from multipotent cells scattered throughout the gastrointestinal (GI) system that belong to the diffuse endocrine system, and have the ability to synthesise and secrete peptides and amines, a number of which can be bioactive (Kaltsas et al. 2004, Modlin et al. 2008). Traditionally, secretory syndromes were attributed to tumours originating from the pancreas (pancreatic NETs, pNETs) and the so-called midgut ('carcinoid') tumours, the majority of which were derived from the ileum (Table 1). More recently, it has become apparent that some of these tumours are capable of secreting substances that are considered to originate from other tissues, making their diagnosis and identification difficult. Furthermore, NETs that were apparently considered to be initially non-functioning may acquire (during the course of the disease) the ability to secrete specific compounds and become functioning, whereas functioning tumours may alter their secretory profile by secreting a different compound (Tomassetti et al. 2001, Kaltsas et al. 2004, Crona et al. 2016). Very recently, a number of newly characterised secretory syndromes that are not previously recognised have been identified, highlighting the need of increased awareness of these functioning NETs and potential alterations of their secretory component in order to identify them and provide appropriate treatment.

In the past, functioning GEP-NETs were associated with increased morbidity and mortality due to the lack of any specific treatment. However, following the demonstration that the majority of GEP-NETs express somatostatin receptors (SSTRs) on their cell surface, and the introduction of long-acting somatostatin analogues (SSAs) that exhibit an overall inhibitory secretory effect in tumours bearing such receptors, significant symptomatic control was obtained in many of the functioning NETs (Kvols et al. 1985, Kaltsas et al. 2004, Modlin et al. 2010). Indeed, patients with a number of secretory syndromes related to GEP-NETs obtained substantial symptomatic and biochemical responses to these agents, although their effect on tumour growth was not as prominent (Modlin et al. 2010). In addition, proton pump inhibitors (PPIs) have also proven to be efficacious in controlling the secretory syndrome related to excessive gastrin secretion (Ito et al. 2013). The introduction of these medications along with the use of various other drugs has resulted in a significant reduction in morbidity and mortality related to functioning GEP-NETs. In addition, the development of more potent SSAs and compounds that inhibit the synthetic pathway of specific bioactive

Table 1 Classification of GEP-NETs according to their secretory component.

\begin{tabular}{|c|c|c|c|}
\hline GEP-NET & Syndrome & $\begin{array}{c}\text { Incidence } \\
\text { (new/100,000 year) }\end{array}$ & Secretory component \\
\hline Carcinoid tumours & Carcinoid syndrome & $2-3$ & Serotonin, tachykinins \\
\hline Gastrinoma & Zollinger-Ellison syndrome (ZES) & $0.5-1.0$ & Gastrin \\
\hline Insulinoma & Endogenous hyperinsulinism & $0.5-1.0$ & Insulin \\
\hline VIPoma & Verner-Morrison syndrome, WDHA & $0.05-0.1$ & VIP \\
\hline Glucagonoma & Glucagonoma & $0.01-0.05$ & Glucagon \\
\hline Somatostinoma & Somatostatinoma & $<0.01$ & Somatostatin \\
\hline ACTHoma & ACTH & $<0.05$ & ACTH \\
\hline GHRHoma & GHRH & Unknown & GHRH \\
\hline pNET causing carcinoid syndrome & Carcinoid syndrome & Unknown & Serotonin, tachykinins \\
\hline pNET causing hypercalcaemia & PTHrPoma & $<0.1$ & PTHrP \\
\hline Rare pNETs & $\begin{array}{l}\text { LH, rennin, GLP-1, IGF-2, } \\
\text { erythropoietin, CCK, } \\
\text { enteroglucagon }\end{array}$ & $1-5$ cases & Various hormones \\
\hline
\end{tabular}

ACTH, adrenocortiocotrophin hormone; CCK, cholecystokinin; GHRH, growth hormone-releasing factor; GLP-1, glucagon-like peptide 1; IGF-2, insulin growth factor 2; LH, luteinising hormone; PTHrP, parathyroid hormone-releasing peptide; VIP, vasointestinal peptide; WDHA, watery diarrhoea hypokalaemia achlorhydria. 
substances has further expanded our therapeutic options. However, a number of secretory syndromes related to GEP-NETs such as the carcinoid syndrome (CS), with or without an associated carcinoid crisis, and malignant insulinomas, along with malignant pheochromocytomas/ paragangliomas, still comprise a significant cause of mortality, as the control of secretory component may still not be possible in many cases.

\section{Rationale for treatment of functioning GEP-NETs with SSAs}

As early as the 1980s, it was demonstrated that native somatostatin (SS-14) could ameliorate many of the symptoms of the CS (Thulin et al. 1978). Because native SS has a relatively short half-life, synthetic compounds mimicking its action but with significantly longer halflives have been developed. Octreotide was the first synthetic SSA exhibiting high affinity for SSTRs type 2 and 5 (SSTR 2,5) to have been introduced into clinical practice (Bauer et al. 1982). Since the majority of GEP-NETs express SSTRs on their surface, it became apparent that they represent ideal targets for these compounds (Kvols et al. 1985, Kaltsas et al. 2004). Initially, subcutaneous (s.c.) injection of octreotide was shown to control symptoms in patients with functioning NETs (Wood et al. 1985) and prevent the development of carcinoid crisis in patients with CS undergoing invasive procedures or surgery (Kvols et al. 1985). The development of a depot formulation of octreotide LAR ('long-acting repeatable') (Novartis), administered at doses of $30 \mathrm{mg}$ at monthly intervals, substantially reduced the need for daily octreotide injections (Rubin et al. 1999). However, the latter can still be used as 'top-up' doses in cases of symptom breakthrough, due to either resistance or waning of the octreotide LAR effect over the month, fluctuations of hormonal levels secreted by the tumour or tumour progression (Rubin et al. 1999, Kaltsas et al. 2004, Modlin et al. 2010). A number of other octapeptide analogues with similar actions to octreotide have also been synthesised, the most extensively used being lanreotide; this is also available in a long-acting formulation, the most convenient being lanreotide autogel (Ipsen). Long-acting SSAs (octreotide and lanreotide) are the best available option for symptom relief from secretory tumours bearing SSTRs on their surface, irrespective of the secretory components being either amines or peptides (Modlin et al. 2010). Furthermore, new synthetic SSAs with affinity for additional SSTRs have been synthesised in an attempt to increase the efficacy of these compounds (Table 2). It has previously been noticed that an escape
Table 2 Native somatostatin and somatostatin receptor subtype-binding affinity of currently available long-acting somatostatin analogues.

\begin{tabular}{|c|c|c|c|c|c|}
\hline Compound & SSTR1 & SSTR2 & SSTR3 & SSTR4 & SSTR5 \\
\hline \multicolumn{6}{|c|}{$\begin{array}{l}\text { Native somatostatin and somatostatin analogue receptor } \\
\text { subtype affinity (IC50, nM) }\end{array}$} \\
\hline Somatostatin-14 & 2.26 & 0.23 & 1.43 & 1.77 & 0.88 \\
\hline Soma & ; & & 3 & - & 0.4 \\
\hline Octreotide & 1140 & 0.56 & 34 & 7030 & 7 \\
\hline Lanreotide & 2330 & 0.75 & 107 & 2100 & 5.2 \\
\hline Pasireotide & 9.3 & 1 & 1.5 & $>100$ & 0.16 \\
\hline
\end{tabular}

SSTR, somatostatin receptor.

phenomenon regarding symptomatic control may develop in patients treated with SSAs over times ranging from a few months to many years (Hofland \& Lamberts 2003). Although this has been merely attributed to desensitisation of tumour-related hormonal secretion by SSAs, it is most commonly encountered following tumour progression and an increase in the secretory component leading to a reduction in the efficacy of SSAs (Hofland \& Lamberts 2003, Kaltsas et al. 2004, Strosberg et al. 2013).

\section{Symptomatic treatment of CS}

The classical (typical) CS is usually characterised by cutaneous flushing, gut hypermobility with diarrhoea and bronchospasm, mostly encountered in patients with small intestinal carcinoids and hepatic metastases (Tomassetti et al. 2001, Kaltsas et al. 2004). A less common atypical CS may be found with tumours originating from the former foregut, mainly lung carcinoids with liver metastases, and is due to the release of both histamine and serotonin (Tomassetti et al. 2001, Papadogias et al. 2007). If CS remains untreated over a prolonged period, it may lead to a number of nutritional deficiencies, the development of carcinoid heart disease (CHD) and other fibrotic changes involving the mesentery (Kaltsas et al. 2004, Grozinsky-Glasberg et al. 2015).

\section{Specific treatment directed against the symptoms of CS}

Before the introduction of SSAs, several therapies aiming at ameliorating symptoms rather than specifically reducing serotonin production were used (Kaltsas et al. 2004, Modlin et al. 2008). Subsequent studies using $150 \mu \mathrm{g}$ of s.c. octreotide three times a day in patients with CS showed an almost $88 \%$ response in flushing and diarrhoea that was accompanied with a greater than $50 \%$ decrease in 5-hydroxyindoleacetic acid (5-HIAA) levels in $72 \%$ of the treated patients (Kvols et al. 1986, Modlin et al.

Published by Bioscientifica Ltd 
2010). Subsequent studies using s.c. octreotide at doses ranging from 50 to $1000 \mu \mathrm{g}$, but occasionally up to $3 \mathrm{mg}$, 2-3 times per day, showed that significant symptomatic improvement of CS was obtained. An analysis of 10 studies that evaluated more than 300 patients with CS treated with s.c. octreotide, with doses ranging between 150 and $3000 \mu \mathrm{g}$ (median dose $450 \mu \mathrm{g}$ ), showed 70\% control of both flushing and diarrhoea (Kvols et al. 1986, Vinik \& Moattari 1989, Anthony et al. 1993, Janson \& Oberg 1993, Saltz et al. 1993, Arnold et al. 1996, di Bartolomeo et al. 1996, Rubin et al. 1999, O'Toole et al. 2000, Aparicio et al. 2001). A randomised study comparing daily s.c. injections of short-acting octreotide to octreotide LAR at various doses every 4 weeks demonstrated an at least equivalent symptomatic control (Rubin et al. 1999). Similar to octreotide LAR, long-acting lanreotide exhibits equal affinity for SSTR type 2 and 5 (Modlin et al. 2010). A pooled data analysis of symptomatic responses (diarrhoea and flushing) to octreotide LAR ( $n=122$ patients) and long-acting lanreotide ( $n=185$ patients) showed a mean symptomatic response of $74.2 \%$ (range $61.9-92.8 \%$ ) and 67.5\% (range 40-100\%), respectively (Modlin et al. 2010). In addition, these agents have the advantage of being associated with a very low side-effect profile and are thus well tolerated (Kaltsas et al. 2004, Modlin et al. 2010, Strosberg et al. 2013). However, potential side effects may occasionally develop and need to be considered, as many patients are treated with these compounds for a prolonged period (Table 3).

When symptom control is inadequate, top-up doses of $50-100 \mu \mathrm{g}$ (up to $1000 \mu \mathrm{g}$ ) of short-acting octreotide s.c. can be given or alternatively the frequency or dose of long-acting SSA administration can be increased (Rubin et al. 1999, Strosberg et al. 2014). In an initial prospective study, 28 patients with CS with disease progression during therapy with octreotide LAR $30 \mathrm{mg}$ every 28 days exhibited complete and partial control of symptoms after octreotide LAR $30 \mathrm{mg}$ administration every 21 days in 40 and $60 \%$ of the cases, respectively; circulating biomarkers were significantly decreased in 30\% (Ferolla et al. 2012).
Significantly higher doses, particularly of octreotide LAR ranging from 40 to $90 \mathrm{mg}$ (Anthony et al. 2011, Fiebrich et al. 2010), have been used in clinical practice in patients with suboptimal symptomatic control of CS or tumour growth while being on the approved maximum label dose of $30 \mathrm{mg}$ every 4 weeks (Rubin et al. 1999). An analysis of a single-centre study evaluating patients treated with $40 \mathrm{mg}$ octreotide LAR every 4 weeks, octreotide LAR $60 \mathrm{mg}$ every 4 weeks and octreotide LAR $30 \mathrm{mg}$ every 3 weeks showed an overall improvement of diarrhoea in 34 (63\%) and flushing in 28 patients (56\%) over conventional dosing (Strosberg et al. 2013). A subsequent multicentre study of 239 patients who had received a series of escalating doses of octreoride LAR also showed a similar beneficial effect in symptom control (Strosberg et al. 2014). However, these studies were hampered by their retrospective nature and the lack of quantitative measurements of changes in flushing and diarrhoea, as all information was collected after reviewing patients' charts (Strosberg et al. 2014). Nevertheless, a significant finding from all these studies was that there was no increased toxicity with doses of octreotide even as high as $120 \mathrm{mg} / \mathrm{month}$ (Anthony et al. 2011, Strosberg et al. 2014, Broder et al. 2015).

Although octreotide and lanreotide target mainly SSTRs 2 and 5, GEP-NETs express multiple subtypes of SSTRs on their surface (Bruns et al. 1994). Pasireotide is a multireceptor targeting SSA with high affinity to all SSTRs except SSTR type 4 (Bruns et al. 2002). It was hypothesised that pasireotide might ameliorate the symptoms of CS in patients inadequately controlled with $30 \mathrm{mg}$ octerotide LAR. In a phase II study, 45 patients with symptoms refractory to $30 \mathrm{mg}$ octreotide LAR, in whom specific criteria to define inadequate control of bowel movements ( $\geq 4$ per day) or flushing episodes ( $\geq 2$ per day) as well as response to treatment were predefined, pasireotide was administered at increasing doses (Kvols et al. 2012). Pasireotide at doses 600-900 $\mu$ g twice daily effectively controlled the symptoms of diarrhoea and flushing in $27 \%$ of the patients, with the most common side effects being nausea, abdominal pain, weight loss

Table 3 Side effects attributed to long-acting somatostatin analogues (data from Van der Lely et al. 1997, Hovind et al. 2010) Frequent side effects $(>10 \%$ of
patients)

Common side effects ( $>1 \%$ of patients)

Rare side effects

Extremely rare side effects
Headaches, fatigue, gastrointestinal symptoms (abdominal pain, cramps, nausea/vomiting, diarrhoea/constipation), biliary tree abnormalities (sludge without stones, gallstones, bile duct dilatation), arthropathy and back pain, insulin secretion abnormalities (hyperglycaemia 10\%, hypoglycaemia $2 \%$ )

Slow heart rate (cardiac conduction changes), skin reactions (pruritus), hyperbilirubinaemia, hypothyroidism, dizziness, dyspnoea

Anaphylactic reactions, pancreatitis, hepatitis Alopecia, QT abnormalities http://erc.endocrinology-journals.org DOI: $10.1530 /$ ERC-16-0200
(C) 2016 Society for Endocrinology Printed in Great Britain
Published by Bioscientifica Ltd. 
and hyperglycaemia (Kvols et al. 2012). A subsequent phase III study that evaluated the ability of pasireotide LAR $60 \mathrm{mg}$ and octreotide LAR $40 \mathrm{mg}$ in controlling the symptoms of CS in patients refractory to currently labelled maximum doses of SSAs demonstrated that both agents showed similar symptomatic control $(20.9 \%$ vs $26.9 \%$, respectively), although pasireotide was associated with a higher incidence of side effects, particularly hyperglycaemia ( $28.3 \%$ vs $5.3 \%$, respectively) (Wolin et al. 2015). From the data derived from this prospective study, the above-labelled octreotide LAR doses (at least octreotide LAR $40 \mathrm{mg}$ ) are expected to induce an approximately 30\% improvement in refractory to conventional doses of SSA symptoms rather than the previously described higher response rates (Strosberg et al. 2013, 2014).

Another agent that has been shown to have activity in controlling the symptoms in patients with CS is interferon- $\alpha$ (Oberg 2000). Initially, human and subsequently recombinant interferon- $\alpha$ were used at doses of 3-9MU daily or on alternate days (median dose $5 \mathrm{MU}$ titrated individually according to sex, weight and age) (Oberg 2000). Although interferon- $\alpha$ controls the symptoms of CS in $40-70 \%$ of the patients, its use is associated with substantial adverse effects including fever, fatigue, anorexia and weight loss, autoimmune diseases and myelosuppression and is considered as a secondline treatment (Kaltsas et al. 2004). Currently, pegylated interferon- $\alpha$ has been introduced that is expected to induce fewer side effects. Considering that interferon- $\alpha$ produces the upregulation of SSTRs in in vitro studies, and the combination with SSAs shows a stronger in vivo antiproliferative effect than either drug alone, it was suggested that their combination might exhibit a synergistic effect (Hofland et al. 1999). This concept was addressed in two prospective studies. In one, lanreotide and interferon- $\alpha$ were shown to exert a superior symptomatic control compared with each compound alone, albeit with more side effects (Faiss et al. 2003). However, there was no difference in respect to symptom control when octreotide alone was compared with the combination of octreotide and interferon- $\alpha$ (Arnold et al. 2005). On the basis of these findings, this combination has not found wide application in clinical practice in terms of symptomatic control, although it has been suggested that lower than previously used doses of interferon- $\alpha$ in combination with SSA may still merit investigation in properly designed randomised trials (Fazio et al. 2007).

For refractory cases that cannot be controlled with long-acting SS analogues (either octreotide or lanreotide), a number of phase I/II and a recent phase III studies have shown that telotristat etiprate, an orally administered serotonin synthesis inhibitor, may have an additional effect (Kulke et al. 2014, Pavel et al. 2015). Telotristat etiprate is a small molecule that does not cross the bloodbrain barrier and thus has no central nervous system side effects, as it does not deplete serotonin levels in the brain (Pavel et al. 2015). Its mode of action is by inhibiting tryptophan hydroxylase, the rate-limiting enzyme in the conversion of tryptophan to serotonin (Kulke et al. 2014). In an initial randomised prospective study designed to assess the safety and efficacy of telotristat in patients with predefined criteria of inadequate symptom control of CS with the highest labelled dose of octreotide LAR, 18 patients were assigned to increasing doses of telotristat etiprate $(150,250,350,500 \mathrm{mg}$ three times daily) and were compared with controls (Kulke et al. 2014). Approximately, $30 \%$ of the patients experienced a $\geq 30 \%$ reduction in bowel movement frequency for $\geq 2$ weeks, whereas $56 \%$ reported adequate relief of at least 1 of the 4 weeks of treatment; adverse effects were generally mild and mainly GI in nature (Kulke et al. 2014). In a subsequent open label with dose escalation over 12 weeks in a prospective study of responses to telotristat in patients refractory to SSAs, 14 patients were evaluated while on concomitant SSA treatment (Pavel et al. 2015). All patients experienced reductions in the number of bowel movements per day (mean decrease, $43.5 \%$ ) associated with additional 5-HIAA level reductions; in addition, stool form and flushing episodes were also improved notwithstanding that the latter are not predominantly serotonin mediated (Pavel et al. 2015). It was thus suggested that telotristat etiprate could offer a further therapeutic option in patients refractory to SSAs, particularly as it is associated with minimal side effects. While these improvements may not seem dramatic, it may also be that the decrease in serotonin synthesis might reduce the onset of peritoneal and especially cardiac valvular fibrosis, which would be valuable therapeutic benefits. Irrespective of advances in currently available drugs, treatment with intravenous octreotide infusion in patients with refractory CS may still be tried, at least temporarily, to provide symptomatic control until treatment debulking options could also be considered.

\section{Non-specific treatment and treatment directed against the sequel of CS}

As diarrhoea and flushing can be induced by specific precipitants, lifestyle adjustments in patients with CS may need to be considered and implemented. Patients

Published by Bioscientifica Ltd 
with diarrhoea should avoid known precipitants such as strenuous exercise, consumption of spicy foods and excessive alcohol intake. Loperamide and codeine phosphate can be of additional help in refractory cases of diarrhoea; loperamide in particular can be used in cases of breakthrough diarrhoea in doses up to $16 \mathrm{mg}$ daily (Kaltsas et al. 2004). Diarrhoea can also result following the resection of the primary tumour and nearby normal bowel at the terminal ileum, secondary to bile acid loss and/or bacterial overgrowth from a blind enteric loop, which may cause deconjugation of bile acids (Kaltsas et al. 2004). Patients with diarrhoea secondary to bile acid deconjugation respond to treatment with cholysteramine or related agents, whereas antibiotics should be administered in cases of bacterial overgrowth (Tomassetti et al. 2001, Kaltsas et al. 2004). The flush of typical CS is usually triggered by alcohol or tyraminecontaining foods, chocolate and bananas. As serotonin is not the main secretagogue, histamine-2 receptor antagonists are also of proven value in this situation (Kaltsas et al. 2004, Papadogias et al. 2007). It should also be remembered that major pancreatic resection, in cases of pancreatic carcinoids, may lead to loss of pancreatic exocrine function, and replacement with enzymes such as Creon with meals may be beneficial. These supplements may also be used to treat SSA-induced steatorrhoea. This is particularly important as a recent study using a validated questionnaire revealed that a significant number of patients with NETs who are on treatment with SSAs are at high risk of malnutrition (Qureshi et al. 2016). Uncontrolled diarrhoea may be debilitating causing dehydration, electrolyte abnormalities, vitamin deficits and hypoproteinaemia (Kaltsas et al. 2004). In the presence of severe CS, the essential amino acid tryptophan is converted to serotonin, leaving inadequate amounts of tryptophan for conversion to niacin and proteins (Bouma et al. 2015). Niacin deficiency can lead to pellagra, with the development of dermatitis, diarrhoea and dementia (Bouma et al. 2015). Other symptoms such as aggression, ataxia, insomnia, confusion and cardiomyopathy may also be present. Diagnosis can be confirmed after rapid improvements in the symptoms in patients using high doses of niacin $(50-500 \mathrm{mg} /$ day) or niacin-enriched food (Kaltsas et al. 2004, Bouma et al. 2015). A combination of vitamin B supplements should be administered to patients with severe diarrhoea and any suspicion of pellagra, and/ or with high 5-HIAA output. In addition, deficiencies of other fat-soluble vitamins, which may occasionally follow treatment with SSAs, should be sought and adequately substituted (Fiebrich et al. 2010).
CHD develops as a result of the fibrotic effect of the excessive amounts of serotonin on heart valvular leaflets. Patients with 5 -HIAA levels $\geq 300 \mu \mathrm{mol} / 24 \mathrm{~h}$ and $\geq 3$ episodes of flushing per day are at increased risk of developing CHD (Bhattacharyya et al. 2011, GrozinskyGlasberg et al. 2015). In case of clinically significant CHD, cardiothoracic surgical evaluation and possible surgical valvular replacement may be required before any major intervention or surgery (Connolly et al. 2001, GrozinskyGlasberg et al. 2015). It is possible that the early use of telotristat etiprate may delay or avoid such problems.

\section{Carcinoid crisis}

Patients with CS are at risk for developing a carcinoid crisis, characterised by excessive flushing, alterations in thermoregulation, bronchospasm and haemodynamic instability, mainly in the form of hypotension (Condron et al. 2016). The crisis may occur following diagnostic or therapeutic procedures, induction of anaesthesia and/or as a result of tumour manipulation (Plöckinger et al. 2004). Intravenous continuous octreotide infusions administered $12 \mathrm{~h}$ before any high-risk procedure at a starting dose of $50-100 \mu \mathrm{g} / \mathrm{h}$ (doses up to $3 \mathrm{mg}$ have been used) with dose escalation until symptom control is obtained (mean dose $100-200 \mu \mathrm{g} / \mathrm{h}$ ) is the treatment of choice (Ramage et al. 2012). Patients pre-treated with SSAs may require even higher doses and treatment should be continued at least $48 \mathrm{~h}$ after the end of the procedure, as late-onset events have been described (Ramage et al. 2012). However, a recent analysis of 127 patients who underwent surgical procedures with concomitant continuous octreotide infusion demonstrated that a carcinoid crisis may still develop, particularly in patients with hepatic metastases and symptoms of CS, although neither was required for a crisis to occur (Condron et al. 2016). Combination treatment with $\mathrm{H} 1$ and $\mathrm{H} 2$ receptor blockers may also be administered, along with glucocorticoids, since histamine release and its peripheral actions are not completely blocked by SS analogues (Kaltsas et al. 2004, Plöckinger et al. 2004) (Fig. 1).

\section{Symptomatic treatment of functioning pNETs}

\section{Insulinomas}

The great majority of insulinomas (>90\%) are identified early and can be surgically cured as they are non-metastatic at presentation (de Herder et al. 2011). Such patients should

Published by Bioscientifica Ltd. 


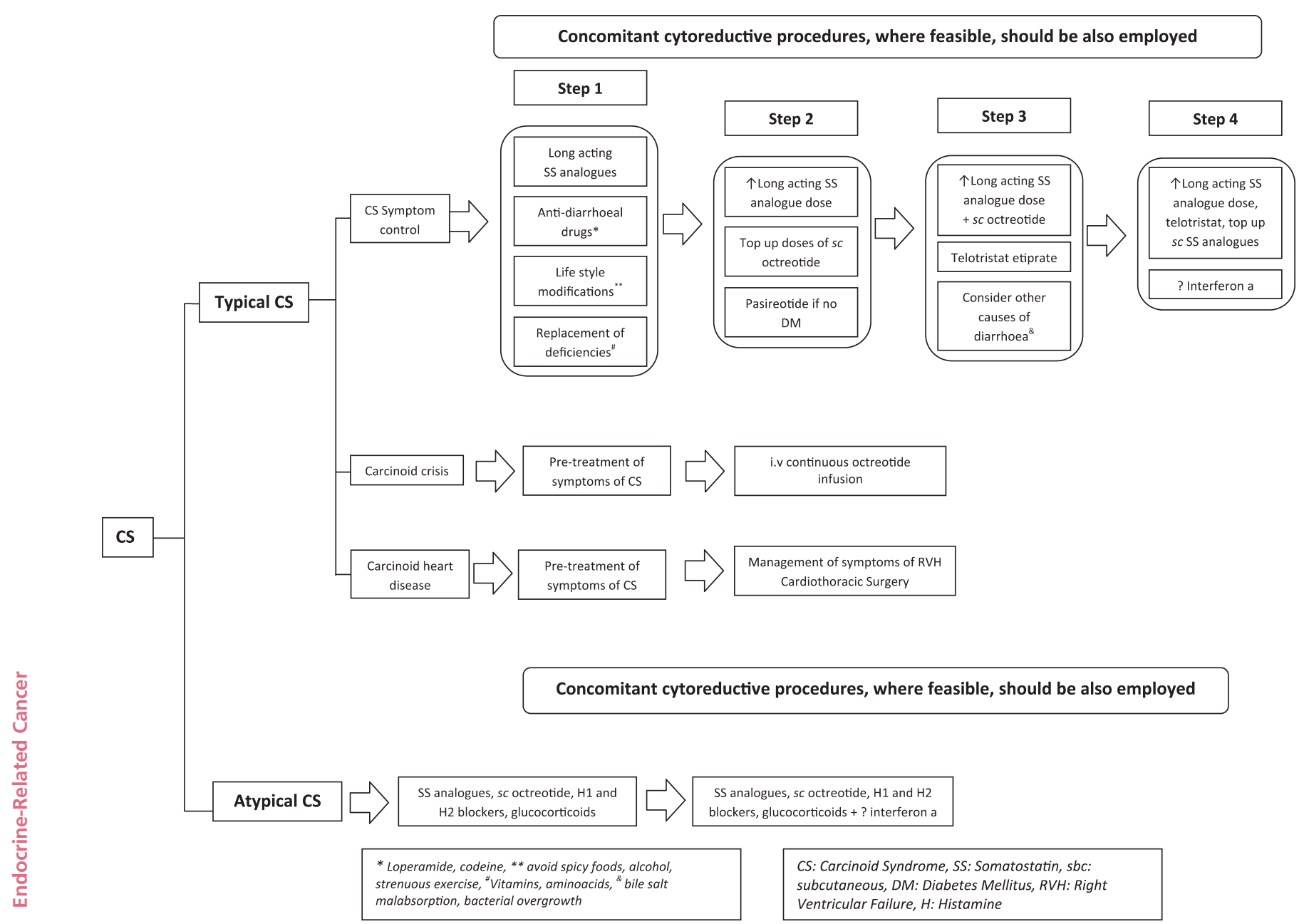

Figure 1

A step-by-step algorithm of management of carcinoid syndrome, carcinoid crisis and sequelae.

preferably be submitted to surgery without delay and often without prior systemic treatment to counteract excessive insulin secretion, as this can be usually controlled with frequent small volume carbohydrate-enriched meals (Kaltsas et al. 2004, de Herder et al. 2011). In insulinoma patients with significant pre-surgical hypoglycaemia, additional symptomatic or systemic therapy may be required. The control of insulin hypersecretion may also be difficult in cases of metastatic tumours not amenable to surgery or other cytoreductive modalities. In such cases, patients may require continuous nocturnal feeding via a nasogastric tube, drugs to lower insulin hypersecretion or even continuous intravenous glucose administration (de Herder et al. 2011, Bernard et al. 2013). At times of intractable hypoglycaemia, high glucose concentration administration along with intra-muscular glucagon and potassium replacement may be required as a rescue procedure. Diazoxide, which suppresses insulin secretion from insulinoma cells via an effect on the ATP-sensitive potassium (KATP) channels, has been extensively used at doses 50-300 mg/day ( $\max$ dose up to $600 \mathrm{mg} /$ day) (Kaltsas et al. 2004, de Herder et al. 2011). This drug has several side effects including GI complaints and oedema, renal impairment and hirsutism, and is usually combined with thiazide diuretics to lower total body potassium and counteract oedema and sodium retention (Kaltsas et al. 2004, de Herder et al. 2011). In addition, there is little information regarding its longterm tolerability and its effect in metastatic insulinomas (Bernard et al. 2013). Although there have been some reports of a hypoglycaemic effect of $\beta$-blockers, calcium blockers and phenytoin, these agents have not been shown to be markedly efficacious in clinical practice (Kaltsas et al. 2004, de Herder et al. 2011). Treatment with long-acting SSAs has been used in patients with insulinomas, but these drugs may worsen hypoglycaemia in approximately 50\% of the cases when tumours lack SSTR2 and 5 expression as

Published by Bioscientifica Ltd 
glucagon secretion is also inhibited; treatment should be initiated only in patients with positive SSTR scintigraphy (SRS) and after the effect of a test dose of octreotide has been evaluated, preferably at an in-patient setting (Bruns et al. 2002, Vezzosi et al. 2005). However, octreotide was shown to be effective in controlling hypoglycaemia in more than $50 \%$ of the patients with insulinomas and a positive SRS, and in a few with negatives scans, whereas there was no relation between treatment efficacy and the expression of SSTR5 (Vezzosi et al. 2005). Other studies have also demonstrated a similar ability of SS analogues in controlling cases of hypoglycaemia (Baldelli et al. 2014). As opposed to benign insulinomas, malignant insulinomas often lack GLP-1 receptors but express SSTR2 receptors in a higher proportion compared with benign lesions, and thus paradoxically respond better to SS analogues (Wild et al. 2011). Furthermore, as pasireotide commonly induces hyperglycaemia, it can also be used in cases of hypoglycaemia not responding to first-generation SS analogues. To date, there is (to our knowledge) only a single case report supporting the beneficial effect of pasireotide in a case of hypoglycaemia refractory to other treatments due to a malignant insulinoma (Tirosh et al. 2016).

In recent years, the mTOR inhibitor everolimus has been shown to exert a specific hyperglycaemic effect and counteract refractory hypoglycaemia in cases of metastatic insulinomas (Kulke et al. 2009, de Herder et al. 2011). The mTOR pathway plays a significant role in pNET progression and also in glucose homeostasis, enhancing insulin secretion and increased glucose utilisation (Bernard et al. 2013). In a number of phase II/III trials with several mTOR inhibitors, hyperglycaemia has emerged as a common side effect suggesting that this is probably a class effect of these drugs (Kulke et al. 2009, Bernard et al. 2013). Several hypotheses have been put forward to explain their hyperglycaemic effect including a decrease in insulin production and release and/or an increase in peripheral insulin resistance (Bernard et al. 2013), but probably decreased insulin release is the predominant therapeutic effect (Korevaar et al. 2014). Everolimus was shown to control refractory hypoglycaemia in four patients with metastatic insulinomas leading to discontinuation of diazoxide and glucose infusions (Kulke et al. 2009). Subsequently, further, patients showing a similar effect have been described, while in a multicentre retrospective study including 12 heavily pre-treated patients with metastatic insulinomas, introduction of everolimus was associated with a median period of normoglycaemia of 6.5 months irrespective of changes in tumour load (Bernard et al. 2013). In this particular study, everolimus appeared to be superior to any other treatments counteracting hyperinsulinaemia, and was mostly given at doses $10 \mathrm{mg} /$ daily; there is, however, evidence that everolimus might still exert a hyperglycaemic effect if given at $5 \mathrm{mg} /$ daily or even on alternate days (Baldelli et al. 2014, Baratelli et al. 2014). In cases of refractory hypoglycaemia from insulinomas not amenable to any cytoreductive techniques, treatment with combination of all these medication may be necessary.

\section{Gastrinoma and the Zollinger-Ellison syndrome}

Zollinger-Ellison syndrome (ZES) occurs as a result of hypersecretion of gastrin, mostly from a GEP-NET of the duodenum or pancreas, although other sources such as thymic carcinoids have been described (Somasundaram et al. 2013). These tumours occur either sporadically or in the context of multiple endocrine neoplasia type 1 (MEN 1) in approximately $25-30 \%$ of the cases (Kaltsas et al. 2004, Jensen et al. 2012). The syndrome should also be suspected in patients with peptic ulcer disease resistant to treatment with PPIs and concomitant diarrhoea, and in the presence of hyperplastic gastric folds - 'rugal hypertrophy' (Kaltsas et al. 2004, Ito et al. 2013). As with other functioning NETs, the therapeutic strategy aims at controlling hormonal excess and tumour growth. However, as complete tumour eradication by surgery is achieved in $<50 \%$ of the patients with sporadic tumours, and in almost none of the patients with MEN 1, unless extensive surgery is performed, long-term treatment of the excessive gastrin secretion and its sequelae is mandatory (Jensen et al. 2012). Traditionally, this has been achieved with the use of medications that counteract gastrininduced hyperchlorhydria such as histamine-2 receptor (H2R) antagonists and PPIs; H2R antagonists (cimetidine and ranitidine) were first used, but due to their short duration of action $(<8-15 \mathrm{~h})$, acid hypersecretion was not adequately controlled, necessitating substantial dose escalation (Schubert \& Peura 2008). Currently, PPIs are regarded as first-line treatment due to their prolonged duration of action (3-4days) and potent inhibition of gastric acid hypersecretion in the majority of patients with ZES (Nieto \& Pisegna 2006, Jensen et al. 2012). High initial doses of PPIs (such as $60-80 \mathrm{mg} /$ day of omeprazole) are frequently prescribed, with dose adjustment as necessary based on symptom response. Additionally, the dose can also be titrated to reduce the acid hypersecretion to $\leq 10 \mathrm{mEq} / \mathrm{h}$, or to lower values in patients with previous acid-reducing surgery or severe

Published by Bioscientifica Ltd 
reflux disease (Ito et al. 2013). Long-term treatment with PPIs has been shown to be safe with the only potential side effects being PPI-induced achlorhydria that may lead to B12 deficiency, although there is a suggestion of an increased incidence of bone fractures (Jensen et al. 2012). SS analogues can also reduce gastrin hypersecterion and may be used in combination with PPIs in rare patients with symptoms refractory to PPIs (Ruszniewski et al. 1993, Granberg et al. 2008). Gastrinomas are predisposed to GI perforation and haemorrhage, which may complicate surgery. During surgery, patients need adequate protection with PPIs to efficiently control the acid hypersecretion (Cisco \& Norton 2007). In the acute setting where oral medications may be contraindicated, intravenous $80 \mathrm{mg}$ of pantoprazole given by $15 \mathrm{~min}$ infusion every $8 \mathrm{~h}$ controlled gastric acid hypersecretion in all ZES patients studied both acutely and up to 7 days (Lew et al. 2000). Patients should maintain their medication with PPIs for some weeks after surgery, since many continue to hypersecrete acid for some time (Ito et al. 2013). Recently, oral gastrin receptor antagonists have also been synthesised that have a rapid mode of action and can induce prolonged gastric acid output suppression (Fossmark et al. 2012). However, their potential role in the treatment has not been investigated as PPIs have been highly active.

\section{Glucagonoma}

Patients with glucagonomas may present with troublesome skin disease (necrolytic migratory erythema) and some patients may be cachectic (Kaltsas et al. 2004, Kindmark et al. 2007). SSA treatment, amino acid infusion and antibiotics may improve the condition and heal the skin lesions in 50-90\% of the patients with glucagonomas, although diabetes mellitus may not substantially improve (Doherty et al. 2005). In addition, parenteral nutrition may also be required to help improve concomitant cachexia, hypoaminoacidaemia and weight loss (Doherty et al. 2005). Patients with glucagonomas have a substantial risk of deep vein thrombosis and pulmonary embolism, and should perioperatively receive prophylactic high-dose molecular heparin as anticoagulation treatment as long as the disease is active (Kaltsas et al. 2004, Kindmark et al. 2007).

\section{VIPoma}

In VIPoma patients, secretory diarrhoea is generally extensive, with severe loss of potassium and bicarbonate leading to metabolic acidosis, dehydration and hypokalaemia (Doherty et al. 2005). VIPomas require meticulous control of high-volume fluid loss as this may lead to severe electrolyte abnormalities and dehydration. Long-acting SS analogues achieve control of the diarrhoea in the majority of such patients, whereas medications such as glucocorticoids, clonidine and loperamide, which were previously used, have, for the most part, been replaced by SSAs. Patients need to be resuscitated from life-threatening fluid losses and electrolyte abnormalities with SSA treatment, as well as intravenous and electrolyte therapy, before being subjected to surgery (Song et al. 2009). There is some evidence that sunitinib, a tyrosine kinase inhibitor, may exert a particular effect in VIPsecreting pNETs regarding symptom and biochemical control irrespective of its effect on tumour growth, and it can thus be used as an adjuvant treatment for symptomatic control in cases of SS analogue-resistant tumours (Bourcier et al. 2013, de Mestier et al. 2015b). As there is a paucity of data regarding regulation of VIP secretion by tumour cells, sunitinib may affect both cyclic adenosine monophosphate and intracellular calcium pathways that have been shown to be implicated in VIP secretion (de Mestier et al. 2015b). However, more information of a potential specific effect on sunitinib on VIP-secreting pNETs is required.

\section{Somatostatinoma}

Although there is no consensus regarding the true incidence of these GEP-NETs, octreotide has been shown to exert activity in cases with symptoms suggestive of an SS-secreting tumour and elevated SS levels (Angeletti et al. 1998).

\section{Unknown and paraneoplastic syndromes}

A number of more rare syndromes attributed to the secretion of bioactive compounds that have not been described are gradually emerging, confirming the multipotent secretory potential of NETs. Recently, a case of cholecystokinin (CCK)-secreting pNET has been identified when high CCK levels were measured in a patient with metastatic pNET, presenting with non-watery diarrhoea, severe weight loss, gallbladder and peptic ulcer disease but normal gastrin levels (Rehfeld et al. 2013). In addition, approximately $3-6 \%$ of the patients with pNETs were shown to secrete multiple hormones at diagnosis, obscuring the clinical phenotype (Crona et al. 2016, de Mestier et al. 2015b). There have also been some reports in the literature of apparently non-functioning pNETs that, during the course

Published by Bioscientifica Ltd 
Table 4 Paraneoplastic syndromes related to GEP-NETs.

\begin{tabular}{|c|c|c|c|c|c|c|}
\hline \multirow[b]{2}{*}{ Syndrome } & \multirow[b]{2}{*}{$\begin{array}{l}\text { Bioactive } \\
\text { substance }\end{array}$} & \multirow[b]{2}{*}{ GEP-NET } & \multicolumn{4}{|c|}{$\begin{array}{l}\text { Features distinguishing PNS from eutopic functioning tumours } \\
\text { and their medical management }\end{array}$} \\
\hline & & & Clinical/biochemical & Endocrine & Radiological & $\begin{array}{l}\text { Symptomatic } \\
\text { management }\end{array}$ \\
\hline Hypercalcaemia & $\begin{array}{l}\text { PTHrP } \\
\text { PTH } \\
\text { Growth factors/ } \\
\text { cytokines }\end{array}$ & $\begin{array}{l}\text { PNET, } \\
\text { carcinoid }\end{array}$ & $\begin{array}{l}\uparrow C a, \downarrow P, \\
\uparrow \text { CAMP urine }\end{array}$ & $\begin{array}{l}\downarrow \mathrm{PTH}, \uparrow \mathrm{PTHrP} \\
\uparrow \mathrm{PTH} \\
\uparrow \mathrm{TGFb}, \uparrow \mathrm{IL}, \uparrow \mathrm{PG}\end{array}$ & $\begin{array}{l}\text { Parathyroid } \\
\text { imaging (-) } \\
\text { CT elsewhere } \\
(+) \\
\text { SRS (+) }\end{array}$ & $\begin{array}{l}\text { Rehydration, } \\
\text { bisphosphonates, } \\
\text { calcitonin, } \\
\text { cinacalcet, dialysis }\end{array}$ \\
\hline $\begin{array}{l}\text { Cushing's } \\
\text { syndrome }\end{array}$ & $\begin{array}{l}\text { ACTH } \\
\text { CRH }\end{array}$ & $\begin{array}{l}\text { PNET, } \\
\text { carcinoid }\end{array}$ & $\begin{array}{l}\text { Cushing's } \\
\text { phenotype }\end{array}$ & $\begin{array}{l}\uparrow \mathrm{ACTH}-\text { isoforms } \\
\uparrow \mathrm{CRH} \\
\mathrm{CRH} / \mathrm{DDAVP} \text { test }\end{array}$ & $\begin{array}{l}\text { Pituitary MRI } \\
\text { (no adenoma) } \\
\text { IPSS (-) } \\
\text { CT/MRI (+) } \\
\text { elsewhere } \\
\text { SRS (+) }\end{array}$ & $\begin{array}{l}\text { Drugs inhibiting } \\
\text { steroidogenesis, } \\
\text { adrenolytics } \\
\text { SS analogues, } \\
\text { dopamine } \\
\text { agonists, } \\
\text { pasireotide }\end{array}$ \\
\hline Acromegaly & $\begin{array}{l}\text { GHRH } \\
\text { GH }\end{array}$ & $\begin{array}{l}\text { PNET, } \\
\text { carcinoid }\end{array}$ & $\begin{array}{l}\text { Acromegaloid } \\
\text { symptoms }\end{array}$ & $\begin{array}{c}\uparrow \mathrm{GH}, \uparrow \mathrm{IGF1} \\
\text { OGTT: no GH } \\
\text { suppression }\end{array}$ & $\begin{array}{l}\text { Pituitary MRI } \\
\text { (no adenoma) } \\
\text { CT/MRI (+) } \\
\text { elsewhere } \\
\text { SRS (+) }\end{array}$ & $\begin{array}{l}\text { SS analogues, } \\
\text { pasireotide, } \\
\text { dopamine } \\
\text { agonists, } \\
\text { pegvisomant }\end{array}$ \\
\hline $\begin{array}{l}\text { Other pituitary } \\
\text { hormones }\end{array}$ & $\begin{array}{l}\mathrm{LH} / \mathrm{FSH} \\
\text { TSH }\end{array}$ & pNET & $\begin{array}{l}\text { Hyperandrogenism } \\
\text { Hyperthyroidism }\end{array}$ & $\begin{array}{l}\uparrow \mathrm{LH}, \text { androgens } \\
\uparrow \mathrm{Ft4}, \mathrm{T3}, \mathrm{TSH}\end{array}$ & $\begin{array}{l}\text { Pituitary MRI } \\
\text { (no adenoma) } \\
\text { CT/MRI (+) } \\
\text { elsewhere } \\
\text { SRS (+) }\end{array}$ & $\begin{array}{l}\text { SS analogues, } \\
\text { dopamine } \\
\text { agonists }\end{array}$ \\
\hline $\begin{array}{l}\text { Vasoactive } \\
\text { peptides }\end{array}$ & $\begin{array}{l}\text { CGRP } \\
\mathrm{Ct}\end{array}$ & pNET & $\begin{array}{l}\text { Vasodilation } \\
\text { Hypotension, } \\
\text { flushing }\end{array}$ & $\begin{array}{l}\uparrow \mathrm{Ct} \\
\text { Ca/pentagastrin } \\
\text { test }\end{array}$ & $\begin{array}{l}\text { Thyroid US (no } \\
\text { nodule) } \\
\text { CT/MRI (+) } \\
\text { elsewhere } \\
\text { SRS (+) }\end{array}$ & $\begin{array}{l}\text { SS analogues, } \\
\text { pasireotide }\end{array}$ \\
\hline Gut hormones & $\begin{array}{l}\text { Ghrelin } \\
\text { Gastrin } \\
\text { VIP } \\
\text { GLP1,2 }\end{array}$ & $\begin{array}{l}\text { pNET/carcinoid } \\
\text { pNET/carcinoid } \\
\text { pNET } \\
\text { pNET }\end{array}$ & $\begin{array}{l}\text { ? Phenotype } \\
\text { ZES } \\
\text { Pancreatic cholera } \\
\text { ? Hypoglycaemia }\end{array}$ & $\begin{array}{l}\uparrow \text { Ghrelin } \\
\uparrow \text { Gastrin } \\
\uparrow \text { VIP }\end{array}$ & $\begin{array}{l}\text { CT/MRI (+), SRS } \\
(+) \\
\text { CT/MRI (+), SRS } \\
(+) \\
\text { CT/MRI (+), SRS } \\
(+), \text { EUS (+) } \\
\text { CT/MRI (+), SRS } \\
(+), \text { EUS (+) }\end{array}$ & $\begin{array}{l}\text { SS analogues, } \\
\text { pasireotide }\end{array}$ \\
\hline Hypoglycaemia & $\begin{array}{l}\text { Insulin } \\
\text { IGF1 } \\
\text { IGF2 } \\
\text { Pro-IGF2 }\end{array}$ & Carcinoid & $\begin{array}{l}\text { Autonomic and } \\
\text { neuroglucopenic } \\
\text { symptoms }\end{array}$ & $\begin{array}{l}\uparrow \text { Insulin } \\
\uparrow \text { IGF1 } \\
\uparrow \text { IGF2 } \\
\uparrow \text { pro-IGF2 }\end{array}$ & $\begin{array}{l}\text { EUS (-) } \\
\text { CT/MRI (+) } \\
\text { elsewhere } \\
\text { SRS (+) }\end{array}$ & $\begin{array}{l}\text { SS analogues, } \\
\text { pasireotide, } \\
\text { everolimus, } \\
\text { glucocorticoids, } \\
\text { GH }\end{array}$ \\
\hline Hypertension & Renin & Carcinoid & $\begin{array}{l}\uparrow \text { Arterial pressure } \\
\text { Hypokalaemiac } \\
\text { alkalosis }\end{array}$ & $\begin{array}{l}\uparrow \text { Renin, } \\
\text { aldosterone }\end{array}$ & $\begin{array}{l}\text { CT adrenals (no } \\
\text { adenoma) } \\
\text { CT/MRI (+) } \\
\text { elsewhere } \\
\text { SRS (+) }\end{array}$ & $\begin{array}{l}\text { SS analogues, } \\
\text { pasireotide }\end{array}$ \\
\hline $\begin{array}{l}\text { Gynaecomastia/ } \\
\text { menstrual } \\
\text { irregularity }\end{array}$ & hCG & pNET & $\begin{array}{l}\text { Gynaecomastia, } \\
\text { menstrual } \\
\text { irregularity } \\
\text { Precocious puberty }\end{array}$ & $\uparrow \mathrm{hCG}$, androgens & $\begin{array}{l}\text { Normal adrenal } \\
\text { and gonadal } \\
\text { imaging } \\
\text { CT/MRI (+) } \\
\text { elsewhere } \\
\text { SRS (+) }\end{array}$ & $\begin{array}{l}\text { SS analogues, } \\
\text { pasireotide }\end{array}$ \\
\hline
\end{tabular}

$\mathrm{ACTH}$, adrenocorticotrophin hormone; CGRP, calcitonin gene-related peptide; $\mathrm{CRH}$, corticotrophin-releasing hormone; $\mathrm{Ct}$, calcitonin; $\mathrm{CT}$, computerised tomography; DDAV, desmopresin; EUS, endoscopic ultrasound; FSH, follicle-stimulating hormone; Ft4, free thyroxine; GH, growth hormone; GHRH, growth hormone-releasing hormone; IGF1, insulin growth factor 1; IPSS, inferior petrosal sinus sampling; LH, luteinising hormone; MRI, magnetic resonance imaging; OGTT, oral glucose-tolerance test; PC, prostagladins; PNET, pancreatic neuroendocrine tumour; PTHrP, parathyroid hormone-related peptide; SRS, somatostatin receptor scintigraphy; SS, somatostatin; $T_{3}$, triodothyronine; TGFb, transforming growth factor; VIP, vasointestinal peptide. 
of the disease, changed their phenotype into functioning tumours (Vashi et al. 2011, Nahmias et al. 2015). Although this phenomenon was originally considered to be unique to non-functioning NETs, it has also been encountered in functioning NETs that alter their secretory component from one bioactive substance to another (Ohn et al. 2013, Nahmias et al. 2015). Recently, two studies have particularly addressed this issue (Crona et al. 2016, de Mestier et al. 2015a). Metachronous hormonal syndromes developed in 15 out of 435 (3.4\%) patients with pNETs after a median of 55 months (de Mestier et al. 2015a). Five of these 15 patients developed insulin and VIP hypersecretion, respectively, whereas the remaining showed gastrin and glucagon hypersecretion; interestingly, the Ki-67 LI increased from 7 to $17.5 \%$ at transformation (de Mestier et al. 2015a). In a further study, 14 of 323 (4\%) patients with pNETs developed metachronous hormonal hypersecretion, whereas this phenomenon was extremely rare in 603 patients with small intestinal NETs (Crona et al. 2016). Median survival was reduced in patients with metachronous hormonal hypersecretion in both studies, and it was worse in those with insulin hypersecretion (Crona et al. 2016, de Mestier et al. 2015a). Since the majority of these tumours had metastasised to the liver, potential therapeutic problems may arise in cases of difficult-to-manage secretory syndromes such as insulin-secreting tumours and CS. Currently, there is limited knowledge regarding the mechanism of tumour transformation and switching in its secretory potential, although NE cells are derived from a pluripotent progenitor cell, which may exhibit considerable plasticity regarding tumour phenotype (Florio 2011). Awareness of such tumoural transformation is of utmost importance for early recognition and treatment of such patients. It is possible that such transformation might be more common than currently recognised, as some of the symptoms may not be specific and difficult to recognise in patients with extensive disease.

Occasionally, the substances secreted by GEP-NET are not directly related to the tissue of origin, the corresponding clinical syndromes being called paraneoplastic (Kaltsas et al. 2010). A high index of suspicion for the presence of such syndromes is required, as, if the clinical presentation is missed, it may delay the diagnosis of the underlying neoplasia and lead to increased morbidity and mortality. The most common of these syndromes encountered in patients with GEP-NETs along with their presentation and symptomatic treatment are shown in Table 4 . Some of these syndromes, such as Cushing's syndrome due to ectopic adrenocorticotrophin hormone (ACTH) and hypercalcaemia due to ectopic parathyroid hormone-related peptide (PTHrP) secretion, may significantly increase the operative risk, and need to be adequately treated before any intervention (Kaltsas et al. 2010, Somasundaram et al. 2013).

\section{Conclusion}

The symptomatic treatment of functioning GEP-NETs has markedly improved following the introduction of long-acting SSAs into clinical practice. There are, however, a number of syndromes for which cytoreductive procedures and SSAs may not be sufficient to ameliorate related symptoms, and further additive treatment is required. In patients with CS inadequately controlled, increasing the dose of the SSA or administration of top-up doses of s.c. octerotide may be needed, whereas the multiligand SSA pasireotide could be effective in patients' refractory to octreotide or lanreotide. The newly introduced serotonin synthesis inhibitor telotristat etiprate has shown to reduce further the symptoms of CS with or without concomitant SSA treatment. Occasionally, combinations of all of these drugs may be required to obtain symptomatic control and reduce the risk of developing long-term complications such as $\mathrm{CHD}$, whereas intravenous continuous octreotide infusion remains the best mean to minimise the risk of carcinoid crisis. Malignant insulinomas may require combination treatment with glucose infusion and diazoxide, whereas everolimus appears to be a new specific treatment for relieving intractable hypoglycaemia. Knowledge of new emerging syndromes, and alterations of the secretory component of previously diagnosed GEPNETs, helps identify underlying previously unsuspected syndromes in patients with extensive disease and provide appropriate treatment.

\section{Declaration of interest}

G K D, M O W and H S R declare that there is no conflict of interest that could be perceived as prejudicing the impartiality of this review. A G and $\mathrm{G} \mathrm{K}$ have received advisory board and pharma funds.

\section{Funding}

This work did not receive any specific grant from any funding agency in the public, commercial or not-for-profit sector.

Author contribution statement

The authors of this manuscript contributed equally to its creation.

\section{References}

Angeletti S, Corleto VD, Schillaci O, Marignani M, Annibale B, Moretti A, Silecchia G, Scopinaro F, Basso N, Bordi C, et al. 1998 Use of the somatostatin analogue octreotide to localise and manage

Published by Bioscientifica Ltd 
somatostatin-producing tumours. Gut 42 792-794. (doi:10.1136/ gut.42.6.792)

Anthony L \& Vinik AI 2011 Evaluating the characteristics and the management of patients with neuroendocrine tumors receiving octreotide LAR during a 6-year period. Pancreas 40 987-994. (doi:10.1097/MPA.0b013e31821f66b4)

Anthony L, Johnson D, Hande K, Shaff M, Winn S, Krozely M \& Oates J 1993 Somatostatin analogue phase I trials in neuroendocrine neoplasms. Acta Oncologica 32 217-223. (doi:10.3109/ 02841869309083915)

Aparicio T, Ducreux M, Baudin E, Sabourin JC, De Baere T, Mitry E, Schlumberger M \& Rougier P 2001 Antitumour activity of somatostatin analogues in progressive metastatic neuroendocrine tumours. European Journal of Cancer 37 1014-1019. (doi:10.1016/ S0959-8049(01)00073-9)

Arnold R, Trautmann ME, Creutzfeldt W, Benning R, Benning M, Neuhaus C, Jürgensen R, Stein K, Schäfer H, Bruns C, et al. 1996 Somatostatin analogue octreotide and inhibition of tumour growth in metastatic endocrine gastroenteropancreatic tumours. Gut $\mathbf{3 8}$ 430-438. (doi:10.1136/gut.38.3.430)

Arnold R, Rinke A, Klose KJ, Müller HH, Wied M, Zamzow K, Schmidt C, Schade-Brittinger C, Barth P, Moll R, et al. 2005 Octreotide versus octreotide plus interferon-alpha in endocrine gastroenteropancreatic tumors: a randomized trial. Clinical Gastroenterology and Hepatology 3 761-771. (doi:10.1016/s1542-3565(05)00481-7)

Baldelli R, Barnabei A, Rizza L, Isidori AM, Rota F, Di Giacinto P, Paoloni A, Torino F, Corsello SM \& Lenzi A 2014 Somatostatin analogs therapy in gastroenteropancreatic neuroendocrine tumors: current aspects and new perspectives. Frontiers in Endocrinology 57. (doi:10.3389/fendo.2014.00007)

Baratelli G, Brizzi MP, Tampellini M, Scagliotti GV, Priola A, Terzolo M, Pia A \& Berruti A 2014 Intermitent everolimus administration for malignant insulinoma. Endocrinology, Diabetes \& Metabolism Case Reports 2014 140047. (doi:10.1530/edm-14-0047)

Bauer W, Briner U, Doepfner W, Haller R, Huguenin R, Marbach P, Petcher TJ \& Pless J 1982 SMS 201-995: a very potent and selective octapeptide analogue of somatostatin with prolonged action. Life Sciences 31 1133-1140. (doi:10.1016/00243205(82)90087-x)

Bernard V, Lombard-Bohas C, Taquet MC, Caroli-Bosc FX, Ruszniewski P, Niccoli P, Guimbaud R, Chougnet CN, Goichot B, Rohmer V, et al. 2013 Efficacy of everolimus in patients with metastatic insulinoma and refractory hypoglycemia. European Journal of Endocrinology 168 665-674. (doi:10.1530/EJE-12-1101)

Bhattacharyya S, Toumpanakis C, Chilkunda D, Caplin ME \& Davar J 2011 Risk factors for the development and progression of carcinoid heart disease. American Journal of Cardiology 107 1221-1226. (doi:10.1016/j.amjcard.2010.12.025)

Bouma G, Van Faassen M, Kats-Ugurlu G, de Vries EG, Kema IP \& Walenkamp AM 2015 Niacin (vitamin B3) supplementation in serotonin producing neuroendocrine tumor patients. Neuroendocrinology 103 489-494. (doi:10.1159/000440621)

Bourcier ME \& Vinik AI 2013 Sunitinib for the treatment of metastatic paraganglioma and vasoactive intestinal polypeptide-producing tumor (VIPoma). Pancreas 42 348-352. (doi:10.1097/ MPA.0b013e31825c53fa)

Broder MS, Beenhouwer D, Strosberg JR, Neary MP \& Cherepanov D 2015 Gastrointestinal neuroendocrine tumors treated with high dose octreotide-LAR: a systematic literature review. World Journal of Gastroenterology 21 1945-1955. (doi:10.3748/ wjg.v21.i6.1945)

Bruns C, Weckbecker G, Raulf F, Kaupmann K, Schoeffter P, Hoyer D \& Lübbert H 1994 Molecular pharmacology of somatostatin-receptor subtypes. Annals of the New York Academy of Sciences 733 138-146. (doi:10.1111/j.1749-6632.1994.tb17263.x)
Bruns C, Lewis I, Briner U, Meno-Tetang G \& Weckbecker G 2002 SOM230: a novel somatostatin peptidomimetic with broad somatotropin release inhibiting factor (SRIF) receptor binding and a unique antisecretory profile. European Journal of Endocrinology 146 707-716. (doi:10.1530/eje.0.1460707)

Cisco RM \& Norton JA 2007 Surgery for gastrinoma. Advances in Surgery 41 165-176. (doi:10.1016/j.yasu.2007.05.010)

Condron ME, Pommier SJ \& Pommier RF 2016 Continuous infusion of octreotide combined with perioperative octreotide bolus does not prevent intraoperative carcinoid crisis. Surgery 159 358-365. (doi:10.1016/j.surg.2015.05.036)

Connolly HM, Schaff HV, Mullany CJ, Rubin J, Abel MD \& Pellikka PA 2001 Surgical management of left-sided carcinoid heart disease. Circulation 104 (Supplement 1) I36-I40. (doi:10.1161/ hc37t1.094898)

Crona J, Norlen O, Antonodimitrakis P, Welin S, STlberg P \& Eriksson B 2016 Multiple and secondary hormonal secretion in patients with metastatic pancreatic neuroendocrine tumours. Journal of Clinical Endocrinology and Metabolism 101 445-452. (doi:10.1210/jc.2015-2436)

de Herder WW, van Schaik E, Kwekkeboom D \& Feelders RA 2011 New therapeutic options for metastatic malignant insulinomas. Clinical Endocrinology 75 277-284. (doi:10.1111/j.1365-2265. 2011.04145.x)

de Mestier L, Hentric O, Cros J, Walter T, Roquin G, Brixi H, Lombard-Bohas C, Hammel P, Diebold MD, Couvelard A, et al. $2015 a$ Metachronous hormonal syndromes in patients with pancreatic neuroendocrine tumors: a case-series study. Annals of Internal Medicine 162 682-689. (doi:10.7326/m14-2132)

de Mestier L, Walter T, Brixi H, Lombard-Bohas C \& Cadiot G 2015b Sunitinib achieved fast and sustained control of VIPoma symptoms. European Journal of Endocrinology 172 K1-K3. (doi:10.1530/eje-14-0682)

di Bartolomeo M, Bajetta E, Buzzoni R, Mariani L, Carnaghi C, Somma L, Zilembo N \& di Leo A 1996 Clinical efficacy of octreotide in the treatment of metastatic neuroendocrine tumors. A study by the Italian Trials in Medical Oncology Group. Cancer 77 402-408. (doi:10.1002/(sici)1097-0142(19960115)77:2<402:: aid-cncr25>3.0.co;2-4)

Doherty GM 2005 Rare endocrine tumours of the GI tract. Best Practice \& Research Clinical Gastroenterology 19 807-817. (doi:10.1016/j.bpg.2005.05.004)

Faiss S, Pape UF, Böhmig M, Dörffel Y, Mansmann U, Golder W, Riecken EO, Wiedenmann B \& International Lanreotide and Interferon Alfa Study Group 2003 Prospective, randomized, multicenter trial on the antiproliferative effect of lanreotide, interferon alfa, and their combination for therapy of metastatic neuroendocrine gastroenteropancreatic tumors - the International Lanreotide and Interferon Alfa Study Group. Journal of Clinical Oncology 21 2689-2696. (doi:10.1200/JCO.2003.12.142)

Fazio N, de Braud F, Delle Fave G \& Oberg K 2007 Interferon-alpha and somatostatin analog in patients with gastroenetropancreatic neuroendocrine carcinoma: single agent or combination? Annals of Oncology 18 13-19. (doi:10.1093/annonc/mdl144)

Ferolla P, Faggiano A, Grimaldi F, Ferone D, Scarpelli G, Ramundo V, Severino R, Bellucci MC, Camera LM, Lombardi G, et al. 2012 Shortened interval of long-acting octreotide administration is effective in patients with well-differentiated neuroendocrine carcinomas in progression on standard doses. Journal of Endocrinological Investigation 35 326-331.

Fiebrich HB, Van Den Berg G, Kema IP, Links TP, Kleibeuker JH, Van Beek AP, Walenkamp AM, Sluiter WJ \& De Vries EG 2010 Deficiencies in fat-soluble vitamins in long-term users of somatostatin analogue. Alimentary Pharmacology \& Therapeutics 32 1398-1404. (doi:10.1111/j.1365-2036.2010.04479.x)
C 2016 Society for Endocrinology Printed in Great Britain 
Florio T 2011 Adult pituitary stem cells: from pituitary plasticity to adenoma development. Neuroendocrinology 94 265-277. (doi:10.1159/000330857)

Fossmark R, Sordal O, Jianu CS, Qvigstad G, Nordrum IS, Boyce M \& Waldum HL 2012 Treatment of gastric carcinoids type 1 with the gastrin receptor antagonist netazepide (YF476) results in regression of tumours and normalisation of serum chromogranin A. Alimentary Pharmacology \& Therapeutics 36 1067-1075. (doi:10.1111/apt.12090)

Granberg D, Jacobsson H, Oberg K, Gustavsson J \& Lehtihet M 2008 Regression of a large malignant gastrinoma on treatment with Sandostatin LAR: a case report. Digestion 77 92-95. (doi:10.1159/000122229)

Grozinsky-Glasberg S, Grossman AB \& Gross DJ 2015 Carcinoid heart disease: from pathophysiology to treatment - 'something in the way it moves'. Neuroendocrinology 101 263-273. (doi:10.1159/000381930)

Hofland LJ \& Lamberts SW 2003 The pathophysiological consequences of somatostatin receptor internalization and resistance. Endocrine Reviews 24 28-47. (doi:10.1210/er.2000-0001)

Hofland LJ, de Herder WW, Waaijers M, Zuijderwijk J, Uitterlinden P, van Koetsveld PM \& Lamberts SW 1999 Interferon-alpha-2a is a potent inhibitor of hormone secretion by cultured human pituitary adenomas. Journal of Clinical Endocrinology and Metabolism 84 3336-3343. (doi:10.1210/jc.84.9.3336)

Hovind P, Simonsen L \& Bülow J 2010 Decreased leg glucose uptake during exercise contributes to the hyperglycaemic effect of octreotide. Clinical Physiology and Functional Imaging 30 141-145. (doi:10.1111/j.1475-097X.2009.00917.x)

Huguet I, Grossman AB \& O'Toole D 2015 Changes in epidemiology of NETs. Neuroendocrinology [in press]. (doi:10.1159/000441897)

Ito T, Igarashi H \& Jensen RT 2013 Zollinger-Ellison syndrome: recent advances and controversies. Current Opinion in Gastroenterology 29 650-661. (doi:10.1097/MOG.0b013e328365efb1)

Janson ET \& Oberg K 1993 Long term management of carcinoid syndrome. Treatment with octreotide alone and in combination with alpha-interferon. Acta Oncologica 32 225-229. (doi:10.3109/02841869309083916)

Jensen RT, Cadiot G, Brandi ML, de Herder WW, Kaltsas G, Komminoth P, Scoazec JY, Salazar R, Sauvanet A, Kianmanesh R, et al. 2012 ENETS consensus guidelines for the management of patients with digestive neuroendocrine neoplasms: functional pancreatic endocrine tumor syndromes. Neuroendocrinology 95 98-119. (doi:10.1159/000335591)

Kaltsas GA, Besser GM \& Grossman AB 2004 The diagnosis and medical management of advanced neuroendocrine tumors. Endocrine Reviews 25 458-511. (doi:10.1210/er.2003-0014)

Kaltsas G, Androulakis II, de Herder WW \& Grossman AB 2010 Paraneoplastic syndromes secondary to neuroendocrine tumours. Endocrine-Related Cancer 17 R173-R193. (doi:10.1677/erc-10-0024)

Kindmark H, Sundin A, Granberg D, Dunder K, Skogseid B, Janson ET, Welin S, Oberg K \& Eriksson B 2007 Endocrine pancreatic tumors with glucagon hypersecretion: a retrospective study of 23 cases during 20 years. Medical Oncology 24 330-337. (doi:10.1007/s12032007-0011-2)

Korevaar TI, Ragazzoni F, Weaver A, Karavitaki N \& Grossman AB 2014 IGF2-induced hypoglycemia unresponsive to everolimus. QJM 107 297-300. (doi:10.1093/qjmed/hcr249)

Kulke MH, Bergsland EK \& Yao JC 2009 Glycemic control in patients with insulinoma treated with everolimus. New England Journal of Medicine 360 195-197. (doi:10.1056/NEJMc0806740)

Kulke MH, O'Dorisio T, Phan A, Bergsland E, Law L, Banks P, Freiman J, Frazier K, Jackson J, Yao JC, et al. 2014 Telotristat etiprate, a novel serotonin synthesis inhibitor, in patients with carcinoid syndrome and diarrhea not adequately controlled by octreotide. Endocrine-Related Cancer 21 705-714. (doi:10.1530/ ERC-14-0173)
Kvols LK, Martin JK, Marsh HM \& Moertel CG 1985 Rapid reversal of carcinoid crisis with a somatostatin analogue. New England Journal of Medicine 313 1229-1230. (doi:10.1056/nejm198511073131916)

Kvols LK, Moertel CG, O'Connell MJ, Schutt AJ, Rubin J \& Hahn RG 1986 Treatment of the malignant carcinoid syndrome. Evaluation of a long-acting somatostatin analogue. New England Journal of Medicine 315 663-666. (doi:10.1056/NEJM198609113151102)

Kvols LK, Oberg KE, O'Dorisio TM, Mohideen P, de Herder WW, Arnold R, Hu K, Zhang Y, Hughes G, Anthony L, et al. 2012 Pasireotide (SOM 230) shows efficacy and tolerability in the treatment of patients with advanced neuroendocrine tumors refractory or resistant to octreotide LAR: results from a phase II study. Endocrine-Related Cancer 19 657-666. (doi:10.1530/ ERC-11-0367)

Lew EA, Pisegna JR, Starr JA, Soffer EF, Forsmark C, Modlin IM, Walsh JH, Beg M, Bochenek W \& Metz DC 2000 Intravenous pantoprazole rapidly controls gastric acid hypersecretion in patients with Zollinger-Ellison syndrome. Gastroenterology 118 696-704. (doi:10.1016/S0016-5085(00)70139-9)

Modlin IM, Oberg K, Chung DC, Jensen RT, de Herder WW, Thakker RV, Caplin M, Delle Fave G, Kaltsas GA, Krenning EP, et al. 2008 Gastroenteropancreatic neuroendocrine tumours. Lancet Oncology 9 61-72. (doi:10.1016/S1470-2045(07)70410-2)

Modlin IM, Pavel M, Kidd M \& Gustafsson BI 2010 Somatostatin analogues in the treatment of gastroenteropancreatic neuroendocrine (carcinoid) tumours. Alimentary Pharmacology \& Therapeutics $\mathbf{3 1}$ 169-188.

Nahmias A, Grozinsky-Glasberg S, Salmon A \& Gross DJ 2015 Pancreatic neuroendocrine tumors with transformation to insulinoma: an unusual presentation of a rare disease. Endocrinology, Diabetes \& Metabolism Case Reports 2015 150032. (doi:10.1530/edm-15-0032)

Nieto JM \& Pisegna JR 2006 The role of proton pump inhibitors in the treatment of Zollinger-Ellison syndrome. Expert Opinion on Pharmacotherapy 7 169-175. (doi:10.1517/14656566.7.2.169)

Oberg K 2000 Interferon in the management of neuroendocrine GEP-tumors: a review. Digestion 62 (Supplement 1) 92-97. (doi:10.1159/000051862)

Ohn JH, Kim YG, Lee SH \& Jung HS 2013 Transformation of nonfunctioning pancreatic neuroendocrine carcinoma cells into insulin producing cells after treatment with sunitinib. Endocrinology and Metabolism 28 149-152. (doi:10.3803/EnM.2013.28.2.149)

O'Toole D, Ducreux M, Bommelaer G, Wemeau JL, Bouché O, Catus F, Blumberg J \& Ruszniewski P 2000 Treatment of carcinoid syndrome: a prospective crossover evaluation of lanreotide versus octreotide in terms of efficacy, patient acceptability, and tolerance. Cancer $\mathbf{8 8}$ 770-776. (doi:10.1002/(sici)1097-0142(20000215)88:4<770::aidcncr6>3.0.co;2-0)

Papadogias D, Makras P, Kossivakis K, Kontogeorgos G, Piaditis G \& Kaltsas G 2007 Carcinoid syndrome and carcinoid crisis secondary to a metastatic carcinoid tumour of the lung: a therapeutic challenge. European Journal of Gastroenterology \& Hepatology 19 1154-1159. (doi:10.1097/MEG.0b013e3282294d88)

Pavel M, Hörsch D, Caplin M, Ramage J, Seufferlein T, Valle J, Banks P, Lapuerta P, Sands A, Zambrowicz B, et al. 2015 Telotristat etiprate for carcinoid syndrome: a single-arm, multicenter trial. Journal of Clinical Endocrinology and Metabolism 100 1511-1519. (doi:10.1210/ jc.2014-2247)

Plöckinger U, Rindi G, Arnold R, Eriksson B, Krenning EP, de Herder WW, Goede A, Caplin M, Oberg K, Reubi JC, et al. 2004 Guidelines for the diagnosis and treatment of neuroendocrine gastrointestinal tumours. A consensus statement on behalf of the European Neuroendocrine Tumour Society (ENETS). Neuroendocrinology 80 394-424. (doi:10.1159/000085237)

Qureshi SA, Burch N, Druce M, Hattersley JG, Khan S, Gopalakrishnan K, Darby C, Wong JL, Davies L, Fletcher S, et al. 2016 Screening for malnutrition in patients with gastro-entero-

Published by Bioscientifica Ltd. 
pancreatic neuroendocrine tumours: a cross-sectional study. BMJ Open 6 e010765. (doi:10.1136/bmjopen-2015-010765)

Ramage JK, Ahmed A, Ardill J, Bax N, Breen DJ, Caplin ME, Corrie P, Davar J, Davies AH, Lewington V, et al. 2012 Guidelines for the management of gastroenteropancreatic neuroendocrine (including carcinoid) tumours (NETs). Gut 61 6-32. (doi:10.1136/ gutjnl-2011-300831)

Rehfeld JF, Federspiel B \& Bardram L 2013 A neuroendocrine tumor syndrome from cholecystokinin secretion. New England Journal of Medicine 368 1165-1166. (doi:10.1056/NEJMc1215137)

Rubin J, Ajani J, Schirmer W, Venook AP, Bukowski R, Pommier R, Saltz L, Dandona P \& Anthony L 1999 Octreotide acetate long-acting formulation versus open-label subcutaneous octreotide acetate in malignant carcinoid syndrome. Journal of Clinical Oncology $\mathbf{1 7}$ 600-606.

Ruszniewski P, Podevin P, Cadiot G, Marmuse JP, Mignon M, Vissuzaine C, Bonfils S \& Lehy T 1993 Clinical, anatomical, and evolutive features of patients with the Zollinger-Ellison syndrome combined with type I multiple endocrine neoplasia. Pancreas $\mathbf{8}$ 295-304. (doi:10.1097/00006676-199305000-00003)

Saltz L, Trochanowski B, Buckley M, Heffernan B, Niedzwiecki D, Tao Y \& Kelsen D 1993 Octreotide as an antineoplastic agent in the treatment of functional and nonfunctional neuroendocrine tumors. Cancer 72 244-248. (doi:10.1002/1097-0142(19930701)72:1<244::aidcncr2820720143>3.0.co;2-q)

Schubert ML \& Peura DA 2008 Control of gastric acid secretion in health and disease. Gastroenterology 134 1842-1860. (doi:10.1053/ j.gastro.2008.05.021)

Somasundaram NP, Garusinghe C, Berney D \& Grossman AB 2013 A thymic carcinoid tumour causing Zollinger-Ellison and Cushing's syndromes due to ectopic ACTH and gastrin secretion. Hormones 12 305-308. (doi:10.14310/horm.2002.1149)

Song S, Shi R, Li B \& Liu Y 2009 Diagnosis and treatment of pancreatic vasoactive intestinal peptide endocrine tumors. Pancreas 38 811-814. (doi:10.1097/MPA.0b013e3181b2bc7c)

Strosberg J, Weber J, Feldman M, Goldman J, Almhanna K \& Kvols L 2013 Above-label doses of octreotide-LAR in patients with metastatic small intestinal carcinoid tumors. Gastrointestinal Cancer Research 6 $81-85$.

Strosberg JR, Benson AB, Huynh L, Duh M, Goldman J, Sahai V, Rademaker AW \& Kulke MH 2014 Clinical benefits of above-standard dose of octreotide LAR in patients with neuroendocrine tumors for control of carcinoid syndrome symptoms: a multicenter retrospective chart review study. Oncologist 19 930-936. (doi:10.1634/ theoncologist.2014-0120)

Thulin L, Samnegård H, Tydén G, Long DH \& Efendić S 1978 Efficacy of somatostatin in a patient with carcinoid syndrome. Lancet 243 . (doi:10.1016/s0140-6736(78)91348-x)

Tirosh A, Stemmer SM, Solomonov E, Elnekave E, Saeger W, Ravkin Y, Nir K, Talmor Y \& Shimon I 2016 Pasireotide for malignant insulinoma. Hormones 15 271-276.

Tomassetti P, Migliori M, Lalli S, Campana D, Tomassetti V \& Corinaldesi R 2001 Epidemiology, clinical features and diagnosis of gastroenteropancreatic endocrine tumours. Annals of Oncology 12 (Supplement 2) S95-S99. (doi:10.1093/annonc/12.suppl_2.s95)

Van der Lely AJ, de Herder WW \& Lamberts SW 1997 A risk-benefit assessment of octreotide in the treatment of acromegaly. Drug Safety 17 317-324. (doi:10.2165/00002018-199717050-00004)

Vashi PG, Gupta D \& Dahlk S 2011 A unique case of a nonfunctional metastatic pancreatic neuroendocrine tumor transforming into an insulin-secreting tumor with an unusual clinical course. Pancreas 40 781-784. (doi:10.1097/MPA.0b013e318212c42d)

Vezzosi D, Bennet A, Rochaix P, Courbon F, Selves J, Pradere B, Buscail L, Susini C \& Caron P 2005 Octreotide in insulinoma patients: efficacy on hypoglycemia, relationships with Octreoscan scintigraphy and immunostaining with anti-sst2A and anti-sst5 antibodies. European Journal of Endocrinology 152 757-767. (doi:10.1530/eje.1.01901)

Vinik A \& Moattari AR 1989 Use of somatostatin analog in management of carcinoid syndrome. Digestive Diseases and Sciences 3 (Supplement) 145-275.

Wild D, Christ E, Caplin ME, Kurzawinski TR, Forrer F, Brändle M, Seufert J, Weber WA, Bomanji J, Perren A, et al. 2011 Glucagon-like peptide-1 versus somatostatin receptor targeting reveals 2 distinct forms of malignant insulinomas. Journal of Nuclear Medicine $\mathbf{5 2}$ 1073-1078. (doi:10.2967/jnumed.110.085142)

Wolin EM, Jarzab B, Eriksson B, Walter T, Toumpanakis C, Morse MA, Tomassetti P, Weber MM, Fogelman DR, Ramage J, et al. 2015 Phase III study of pasireotide long-acting release in patients with metastatic neuroendocrine tumors and carcinoid symptoms refractory to available somatostatin analogues. Drug, Design, Development and Therapy 9 5075-5086. (doi:10.2147/dddt.s84177)

Wood SM, Kraenzlin ME, Adrian TE \& Bloom SR 1985 Treatment of patients with pancreatic endocrine tumours using a new long-acting somatostatin analogue symptomatic and peptide responses. Gut 26 438-444. (doi:10.1136/gut.26.5.438)

Received in final form 15 July 2016

Accepted 26 July 2016

Accepted Preprint published online 26 July 2016
() 2016 Society for Endocrinology Printed in Great Britain
Published by Bioscientifica Ltd. 